\title{
Sukhoi SU-47 Berkut and Eurofighter Typhoon Models Flow Visualization and Performance Investigation Using GAMA Water Tunnel
}

\author{
Sutrisno $^{1}$, Febryanto Nugroho ${ }^{2}$, Yogi Adi Pratama ${ }^{1}$, Sigit Iswahyudi ${ }^{1,3} \&$ Setyawan Bekti Wibowo ${ }^{1,2}$ \\ ${ }^{1}$ Department of Mechanical and Industrial Engineering, Faculty of Engineering, Universitas Gadjah Mada, \\ Indonesia \\ ${ }^{2}$ Department of Mechanical, Vocational College, Universitas Gadjah Mada, Yogyakarta 55281, Indonesia \\ ${ }^{3}$ Department of Mechanical Engineering, Universitas Tidar, Magelang 56116, Indonesia \\ Correspondence: Sutrisno, Department of Mechanical and Industrial Engineering, Faculty of Engineering, \\ Universitas Gadjah Mada, Yogyakarta 55281, Indonesia. Tel: 62-8962-266-9341. E-mail: sutrisno@ugm.ac.id.
}

Received: Nov. 23, 2018

Accepted: Dec. 4, 2018

Online Published: January 3, 2019

doi:10.5539/mas.v12n12p21

URL: https://doi.org/10.5539/mas.v12n12p21

The research is financed by the Department of Mechanical \& Industrial Engineering, Universitas Gadjah Mada, Indonesia.

\begin{abstract}
Changes and modifications to the wings of fighter aircraft were carried out, one of which was the forward swept wing which was a moderate wing that continues to develop. There were also types of delta wings that had been applied to many fighter planes. Both types of aircraft wings had certainly different aerodynamic characteristics. This research would study the flow visualization that occurs in the aircraft model body to determine the aerodynamic characteristics of the forward swept wing and delta wing. This study used a water tunnel to observe the aerodynamic flow and forces that occurred in both types of wings. This visualization test used similar aircraft models: SU-47 Berkut and Eurofighter Typhoon. The results provided flow visualization, coefficient of lift $(\mathrm{Cl})$, and coefficient of drag $(\mathrm{Cd})$ which showed that the stall that occurred on the aircraft model similar to the SU-47 Berkut occurred at an angle of attack (AoA) $50^{\circ}$ with a $\mathrm{Cl}$ max value of 2.66. Meanwhile, the Eurofighter Typhoon stall model occurred at an angle of attack $45^{\circ}$ with a $\mathrm{Cl}$ max value of 1.48 .
\end{abstract}

Keywords: aerodynamic, water tunnel, flow visualization, Sukhoi Su-47 Berkut, Eurofighter Typhoon, a fighter

\section{Introduction}

The aerodynamic design of an aircraft continues progressing since its introduction in the 1920s. Previous research activities on aircraft design aim to reduce drag and usually focus on wing design, drag, lift, and especially on airfoil design. However, at high-speed conditions, precise aircraft design is significant to reduce the total drag of an aircraft and improve flight performance (Simpson, 2001). Airplane performance, such as maximum flight speed or fuel consumption, depends on the drag and lift coefficient which can be improved with better aerodynamic design (Della Vecchia \& Nicolosi, 2014). One of the essential items in the aerodynamic design of a plane is the meeting between the wing and body. This meeting was identified as a body relationship with different aircraft components, in the particulars of the wing and body shape of the aircraft. This meeting induces interactions between components, especially the combined boundary layer which causes flow phenomena to be complicated to explain and simulate (Simpson, 2001).

Fuselage effect in fighter aircraft is another case. The fuselage effect is the interaction between the body, main wing, and canard. Fighter fuselage influences vortex dynamics and lifts force generation. Some researchers have observed the influence of the fuselage on the dynamics of vortices that occur. Sutrisno et al. observed the effect of the fuselage on vortex canard formation on J-10 aircraft models (Sutrisno et al., 2018). The research results showed that the higher efficiency of the canard wing, the more negative pressure of the fuselage models. Therefore, as a pitching moment is more significant, due to the higher axial vortex velocity, the vortex breakdown location shifted further away. 
The formation of the fuselage vortex on the X-31 plane model has been observed (Boelens, 2012). The interaction between vortex core forebody and LEX in the F-18 plane model has also been investigated (Delfrate, Zuniga, \& Fisher, 1991; L. P. Erm, 2003). Several previous researchers have observed many fuselage effects on types of straight type fighter aircraft body models such as Chengdu, X-31 and F-18. Fighter aircraft is one of the extraordinary machinery, especially in the field of defense technologies. The shape and size of fighter planes are also continually undergoing changes and modifications with time. Configuration and form change and modifications are made to improve the performance of the previous shape. Changes and modifications were carried out primarily on the shape of a fighter's wing.

Lately, passenger aircraft environment and its future design have been thoroughly explored. Zahari et al. have learned the trade-off between optimizing flight patterns and human health, especially on aircraft noise (Zafari, Jiao, Will, Li, \& Muennig, 2018). Jiao has reported the cost-effectiveness of lowering permissible noise levels around US airports (Jiao, Zafari, Will, Ruggeri, \& Li, 2017). Foster has learned a generic approach to analyze the impact of a future aircraft design on the boarding process (Id, Förster, \& Id, 2018). Cezary et al. have proposed electric propulsion concepts for an inverted joined wing airplane demonstrator (Cezary Galinski, Lis, \& Hajduk, 2017). Some scientist deeply investigated the development and testing of a low-cost instrumentation platform for fixedwing UAV performance analysis (Dapper, Cabreira, \& Freitas, 2018). Zhang et al. have conducted research on local humidity environment of ground parking aircraft (Zhang, Zhang, He, Du, \& Ma, 2018).

Several eminent scientists have explored numerical investigation to some fighters. Boelens have conducted CFD analysis of the flow around the X-31 aircraft at a high angle of attack (Boelens, 2012). Chen et al. have studied the effect of sideslip on high angle of attack (AoA) vortex flow over a close-coupled canard configuration (Chen, Liu, Guo, \& Qu, 2016). Ghoreyshi et al. have performed simulation validation of static and forced motion flow physics of a canard configured TransCruiser (Ghoreyshi, Korkis-Kanaan, Jirasek, Cummings, \& Lofthouse, 2016). Ghoreyshi et al. have learned transonic aerodynamic load modeling of X-31 aircraft pitching motions (Ghoreyshi, Cummings, Ronch, \& Badcock, 2013). Schütte and Rein have examined experimental and numerical aspects of simulating unsteady flows around the X-31 configuration (Schütte \& Rein, 2007).

There are two types of canard fighter body configurations, a typical or straight type aircraft configurations are Euro-fighter (Germany), Rafale (France), Grippen (Sweden), and Chengdu (China). The other type is a curved bird body-fuselage is a configuration type of Sukhoi (Russia) type aircraft body. In the present time, the performance of two aircraft is compared. One aircraft, its development has been carried out employing forward swept wings which is a moderate wing. The Sukhoi Su-47 Berkut aircraft that uses the front sweeper wing are prototype aircraft that are still being developed. The other type is aircraft with delta wings that have been applied to many fighter planes. The second is the Eurofighter Typhoon that uses the delta wing. The fighter has been widely used in defense in various countries. Both types of aircraft wings have certainly different aerodynamic characteristics.

Formation of the flow around the aircraft is essential to see the aerodynamic character of an aircraft so that visualization of the flow on the plane becomes very important. From visualization one can suggest the improvement of the aircraft performances. The test tool used for this research is a water tunnel. Water tunnels are commonly used in visualizing the aerodynamic characteristics of aircraft because they have the advantage of more detailed visualization results (Lincoln P Erm \& Ol, 2012). Using the water tunnel will obtain visualization of the flow that occurs. In this project, research is focused on flow visualization to see aerodynamic comparisons of two types of fighter aircraft that have front sweep wings and delta wings.

The use of a water tunnel will make it easier to reveal the phenomena that occur. For a long time, many studies have used water tunnels to see a visualization of flow testing on moving objects or fluid flow, especially on fighter aircraft. The vortex phenomenon of breakdown location that occurs on the delta wing has been observed using water tunnel by (L. P. Erm, 2003; Lincoln P Erm \& Ol, 2012; Jaroszewicz, Stachow, Sibilski, \& Zyluk, 2011; Lu $\&$ Zhu, 2004). In addition, water tunnels have also been widely used to observe the phenomenon of vortex dynamics above the LEX wing in F/A-18 aircraft models by (Cotton \& Bjarke, 1994; Erickson, 1982; Lincoln P Erm \& Ol, 2012; Sandlin \& Ramirez, 1991; Suarez, Malcolm, Kramer, Smith, \& Ayers, 1994; Thompson, 1990, 1997; Wibowo, Sutrisno, \& Rohmat, 2018; Wibowo, Sutrisno, Rohmat, et al., 2018). The use of water tunnels is perfect for studying flow visualization because it has a higher density and a lower mass diffusion than air (Lincoln P Erm, 2007). So, this study focuses on observing the effect of fuselage variations on vortex dynamics and aerodynamic performance on aircraft models similar to the Sukhoi Su-30MKI using GAMA water tunnel.

The fighter models used in this study were the Sukhoi Su-47 Berkut-like fighter aircraft which had a forward swept wing and a Eurofighter Typhoon-like fighter aircraft which had a delta wing. The study focused on the aerodynamic 
performance comparison between a Sukhoi Su-47 fighter-like fighter model and a Eurofighter Typhoon-like model. The comparison included their lift and drag, and the research was conducted in a water tunnel.

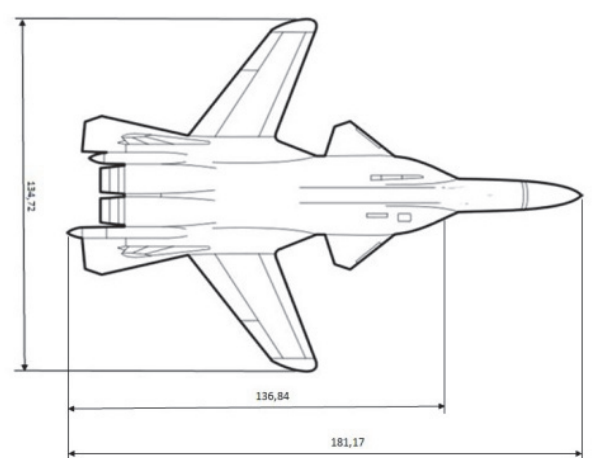

(a)

(c)

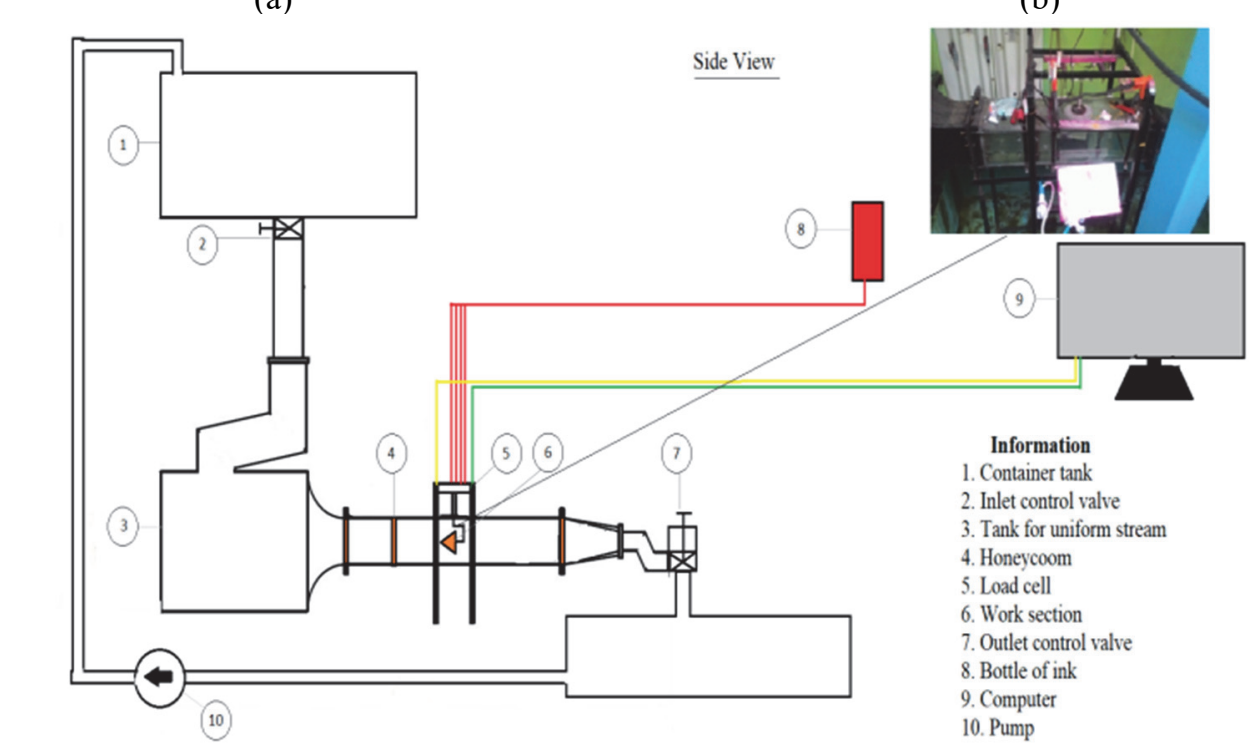

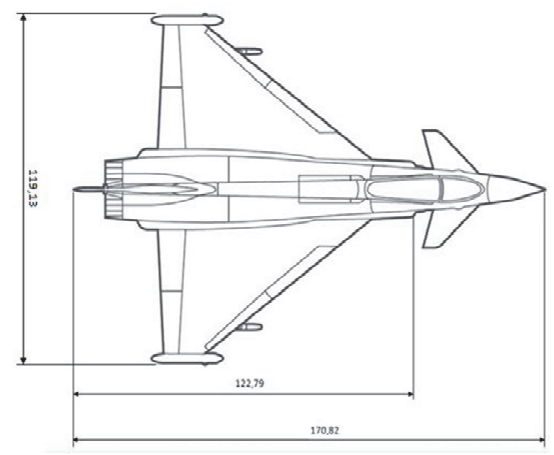

(b)

Figure 1. Research equipment, (a) geometry of Sukhoi Su-47 aircraft models, (b) geometry of Eurofighter Typhoon aircraft models, (c) GAMA Water Tunnel facilities

\section{Method}

This research has been conducted to find out the visualization of fluid flow patterns and analyzing the ratio of lift and drag force experienced in the Sukhoi Su-47 Berkut and Eurofighter Typhoon aircraft models in certain positions using water tunnel. This study used a facility called GAMA Water Tunnel with a flow rate setting of 0.1 $\mathrm{m} / \mathrm{s}$ as shown in Figure 1(c). Water has flowed from the tank to the pond through honeycomb and the test section. By using the GAMA Water Tunnel facility, we have obtained the results of flow visualization, the coefficient of lift $(\mathrm{Cl})$ value, and coefficient of drag $(\mathrm{Cd})$ value. This study has been used a model similar to $\mathrm{Su}-47$ Berkut and Eurofighter Typhoon aircraft as shown in Figure 1(a) and 1(b). As a guide to the flow phenomenon that occurs, the ink has come out through the hole in the plane model and follow the flow on the aircraft model wing. Tests have been carried out with angles of attack $0^{\circ}$ to $70^{\circ}$. 


\section{Results}

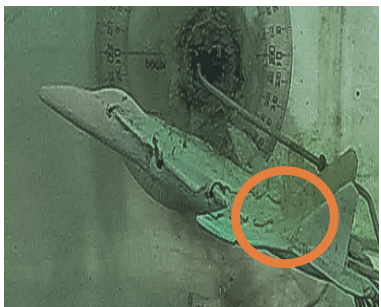

(a) $\mathrm{Su}-47-\mathrm{AoA} 20^{\circ}$

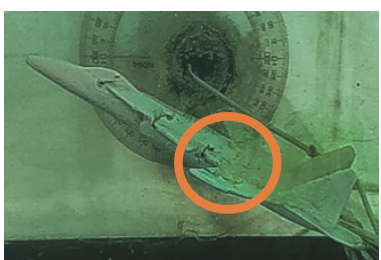

(e) $\mathrm{Su}-47-\mathrm{AoA} 30^{\circ}$

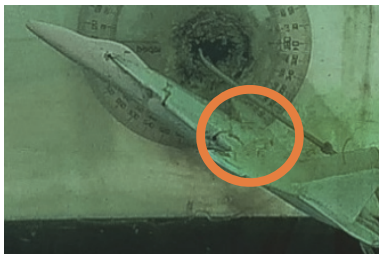

(i) $\mathrm{Su}-47-A o A 40^{\circ}$

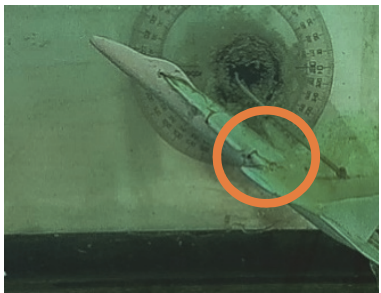

(m) $\mathrm{Su}-47-A o A 45^{\circ}$

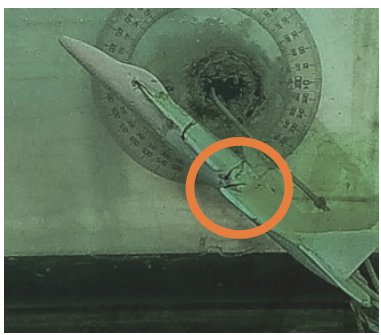

(q) Su-47-AoA50

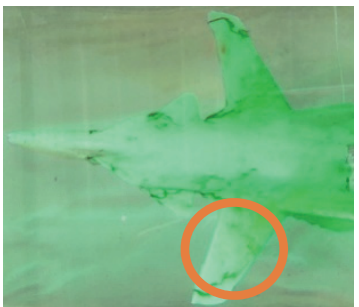

(b) Su-47 - AoA20

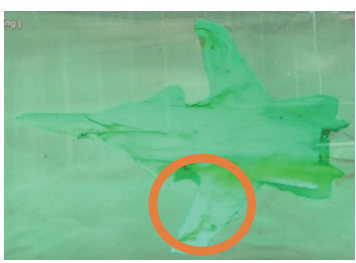

(f) $\mathrm{Su}-47-A o A 30^{\circ}$

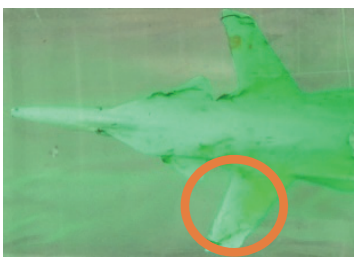

(j) $\mathrm{Su}-47-A o A 40^{\circ}$

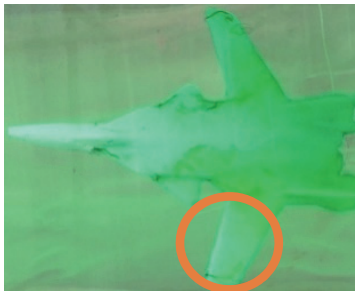

(n) $\mathrm{Su}-47-A o A 45^{\circ}$

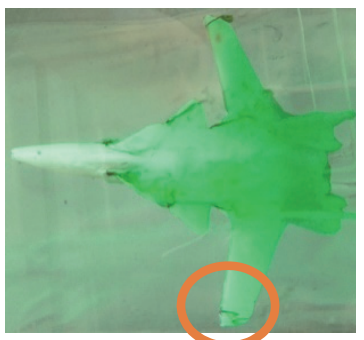

(r) $\mathrm{Su}-47-A \circ A 50^{\circ}$

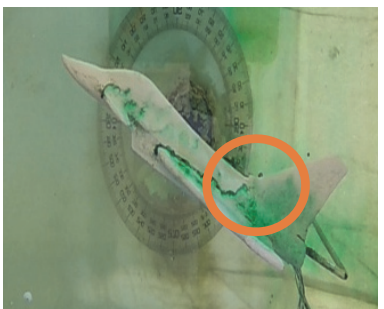

(c) EF Typhoon- $A o A 20^{\circ}$

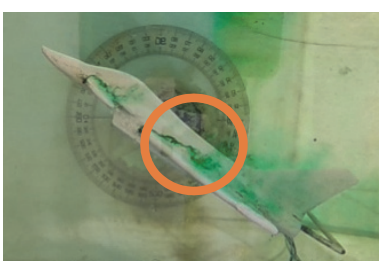

(g) EF Typhoon $-A o A 30^{\circ}$

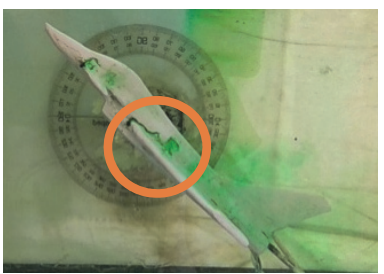

(k) EF Typhoon $-A o A 40^{\circ}$

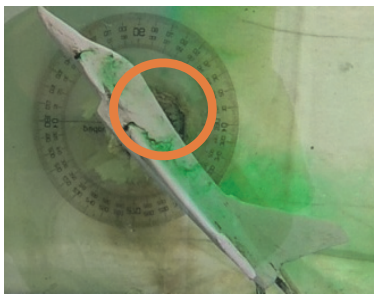

(o) EF Typhoon - $A o A 45^{\circ}$

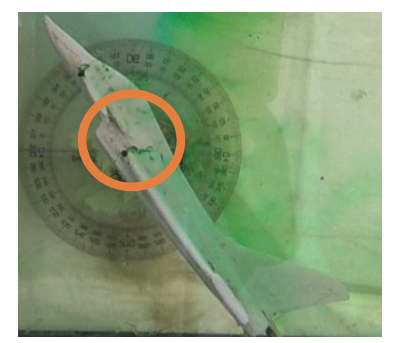

(s) EF Typhoon $-A o A 50^{\circ}$

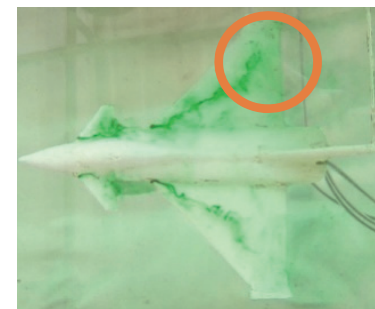

(d)EF Typhoon $-A o A 20^{\circ}$

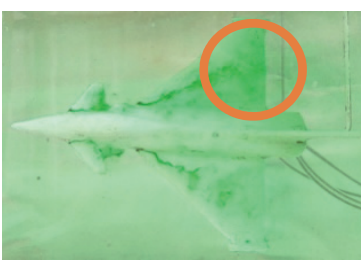

(h) EF Typhoon AoA30 ${ }^{\circ}$

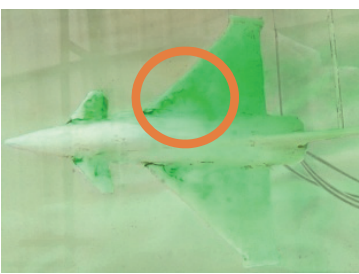

(1) EF Typhoon $-A o A 40^{\circ}$

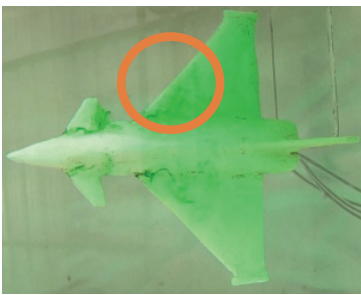

(p) EF Typhoon AoA45 ${ }^{\circ}$

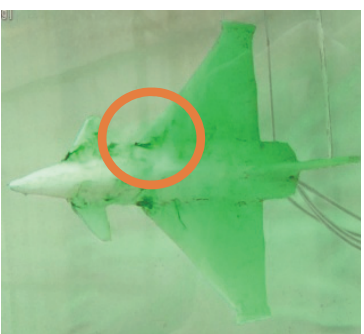

(t) EF Typhoon $-A o A 50^{\circ}$

Figure 2. Results of visualization of vortex cores on Sukhoi Su-47 and Eurofighter Typhoon aircraft models on $\mathrm{AoA}=20^{\circ}, 30^{\circ}, 40^{\circ}, 45^{\circ}, 50^{\circ}$

From the test, the results of AoA $20^{\circ}$ visualization on the $\mathrm{Su}-47$ model Figure $2 \mathrm{a}$ and $2 \mathrm{~b}$ showed that the vortex breakdown $(\mathrm{Vb})$ occurred on $13 / 15$ part of the main wing, the $2 \mathrm{c}$ and $2 \mathrm{~d}$ Typhoon aircraft models showed $\mathrm{Vb}$ occurred on 22/25 main wing. The result of visualization of AoA $30^{\circ}$, Figure $2 \mathrm{e}$ and $2 \mathrm{f}$ for Su-47 showed that $\mathrm{Vb}$ occurred in $2 / 3$ parts of the main wing, Figure $2 \mathrm{~g}$ and $2 \mathrm{~h}$. for Typhoon shows $\mathrm{Vb}$ occurred on $4 / 5$ parts of the main wing. The visualization result of AoA $40^{\circ}$ Figure $2 \mathrm{i}$ and $2 \mathrm{j}$ on the $\mathrm{Su}-47$ showed that $\mathrm{Vb}$ occurred in half the main wing, while Figure $2 \mathrm{k}$ and $2 \mathrm{l}$ on Typhoon show $\mathrm{Vb}$ occurred on $2 / 5$ parts of the main wing. The visualization result 
of AoA $45^{\circ}$, Figures $2 \mathrm{~m}$ and $2 \mathrm{n}$ on the Su-47 showed Vb occurred in $1 / 3$ of the main wing, while Figure $2 \mathrm{o}$ and $2 \mathrm{p}$ on Typhoon showed $\mathrm{Vb}$ occurred in $1 / 6$ of the main wing. The visualization results of AoA $50^{\circ}$ Figure $2 \mathrm{q}$ and $2 \mathrm{r}$ on the Su-47 showed that $\mathrm{Vb}$ occurs in $1 / 5$ of the main wing, while Figure $2 \mathrm{~s}$ and $2 \mathrm{t}$ on Typhoon have not formed vortex cores.

Figure 3 showed the vortex chart breakdown location against AoA which indicates the position of the vortex breakdown in the main wing. Greater vortex breakdowns were formed closer to the leading-edge main wing if the AoA value increases. This has been evidenced by the decreasing $\mathrm{x} / \mathrm{L}$ value when the AoA value has been enlarged.

In the Typhoon aircraft model at an AoA $45^{\circ}$, there has been no lift which means that in this condition, while the $\mathrm{Su}-47$ aircraft model at an AoA $50^{\circ}$ there has been no lift or was called a plane experiencing stall. $\mathrm{Cl}$ measurement results on the $\mathrm{Su}-47$ plane model and Typhoon plane model are shown in Figure 4 . From the $\mathrm{Cl}$ test, the highest $\mathrm{Cl}$ value is obtained at a particular angle of attack. The highest $\mathrm{Cl}$ value has been called $\mathrm{Cl}$, max. The $\mathrm{Cl}$, max value in the Su-47 aircraft model is 2.66 at an $\mathrm{AoA} 50^{\circ}$. The $\mathrm{Cl}$, max value on the Typhoon plane model was 1.48 at an AoA $45^{0}$.

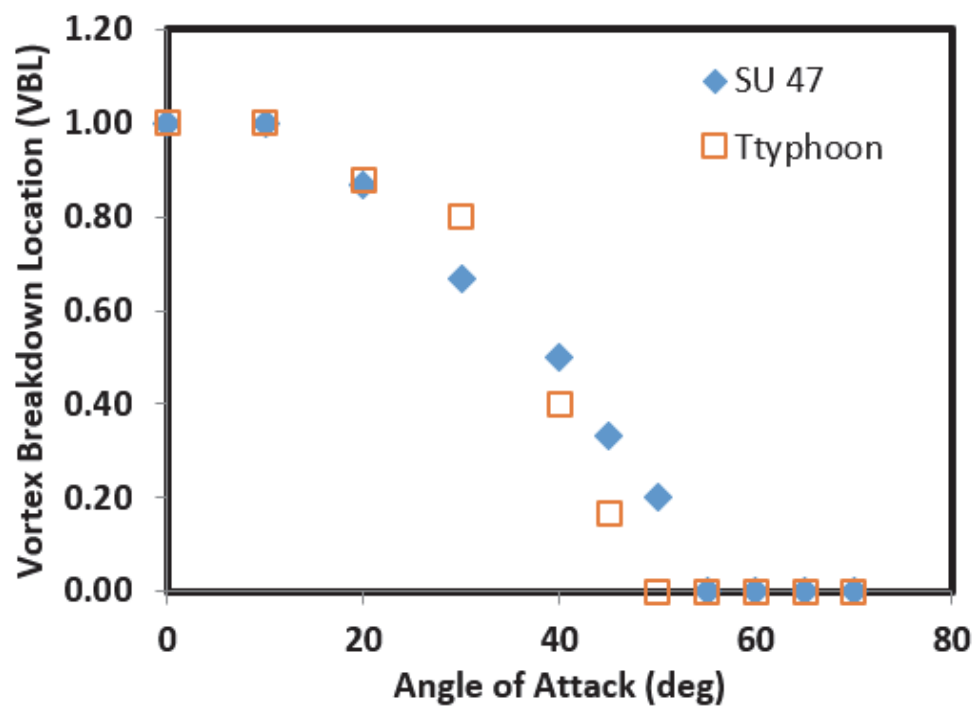

Figure 3. Vortex chart breakdown location of AoA

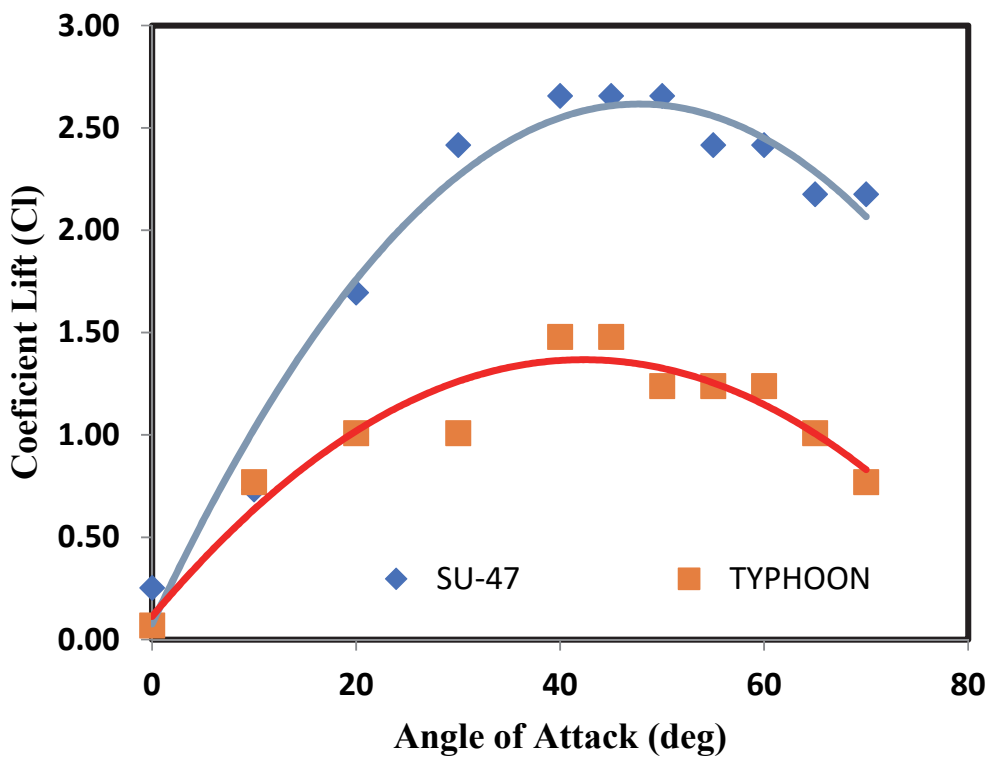

Figure 4. $\mathrm{Cl}$ comparison graph for Sukhoi Su-47 and Eurofighter Typhoon 
Figure 4 on the Su-47 plane model and Typhoon plane model showed that after the $\mathrm{Cl}$ value has been at the highest value, then the AoA value has been enlarged, resulting in a decrease in $\mathrm{Cl}$ value and a stall condition. From the results of the drag measurement of AoA, Figure 5 showed the $\mathrm{Cd}$ value of the two aircraft models. The Cd value on both aircraft models would increase if the angle of attack (AoA) on the plane rises. Each aircraft model showed the highest $\mathrm{Cd}$ at $\mathrm{AoA} 70^{\circ}$. In the Su-47 aircraft model when $\mathrm{AoA} 70^{\circ}$ the $\mathrm{Cd}$ value has been 2.65 and on the Typhoon plane model when AoA $70^{\circ}$ the Cd value was 1.52 . The results showed that the Berkut Su-47 plane model began to decrease lift at an AoA $50^{\circ}$ with $\mathrm{Cl}$, max value of 2.66, while in the Typhoon plane model the lift force occurred at an AoA $45^{\circ}$ with $\mathrm{Cl}$, max value amounting to 1.48. Figure 6 showed the lift to drag coefficient comparison graph for Sukhoi Su-47 and Eurofighter Typhoon. It displayed that the lift to drag ratio of Sukhoi Su47 was truly strong compared to Eurofighter Typhoon.

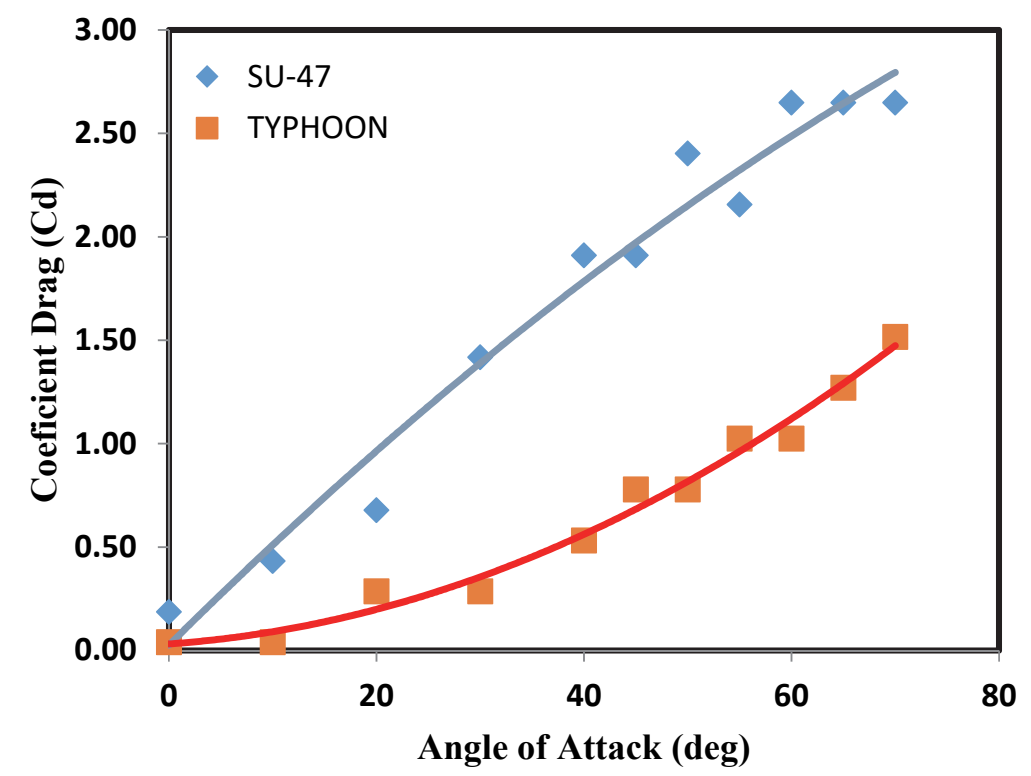

Figure 5. Cd comparison graph for Sukhoi Su-47 and Eurofighter Typhoon

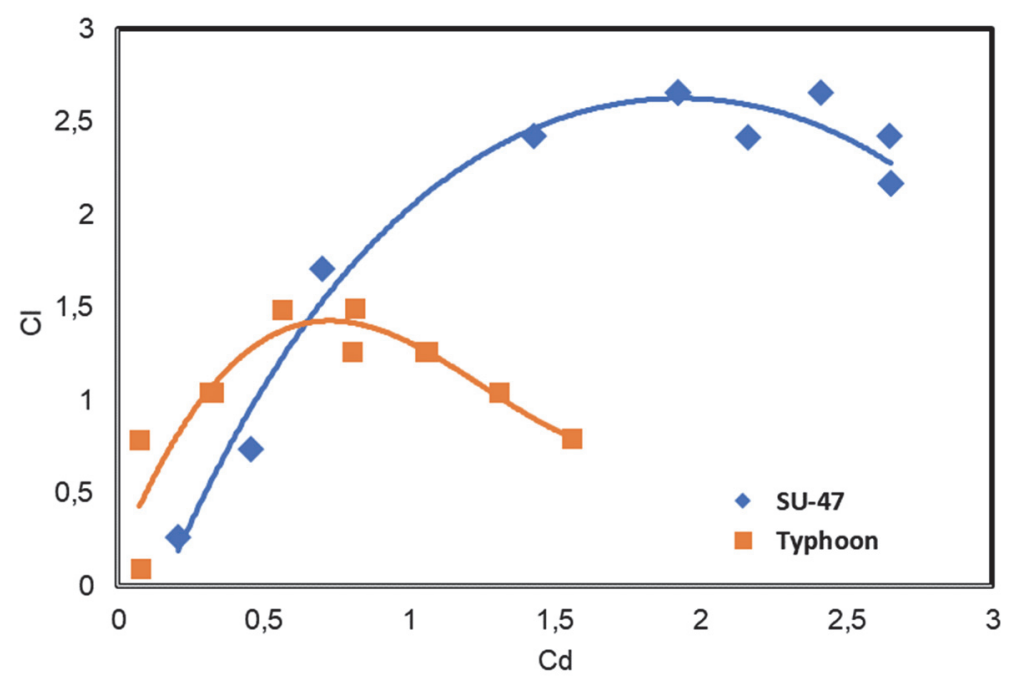

Figure 6. $\mathrm{Cl}$ vs. Cd, lift to drag comparison graph for Sukhoi Su-47 and Eurofighter Typhoon

\section{Discussion}

Physical comparison between Su-47 and Eurofighter Typhoon could be explained as follows. Su 47 has canard 
foreplanes and cranked-arrow delta wing, with intakes under the wing roots. The wing has a one-piece flap inboard and an aileron outboard on the trailing edge of the wing, plus a drooping leading-edge flap. All-moving canard foreplanes are ahead of the wings. The tail arrangement features all-moving tailplanes and twin tailfins with rudders.

According to many experts, Su-47 has a forward-swept wing (FSW) configuration, which features a leading-edge sweep of 20 degrees. It uses a highly unstable triplane, with three main lifting aerodynamic surfaces configuration. Competed to a swept-back wing of the same area, it offers some advantages: higher lift to drag ratio, higher capacity in dogfight maneuvers, higher range covered at subsonic speed. It improves stall resistance and anti-spin characteristics it enhances stability at high AoA, a lower minimum flying speed, a shorter take-off, and landing distance. The forward swept mid wing gives the characteristic positive of the Su-47. An important part of the lifting force generated by the FSW arises at the inner part of the wingspan. The lift is not constrained by wingtip stall. The ailerons remain valid at the highest AoA, and the aircraft controlling is reserved even in the event of airflow separating from the rest of the wings' surface (flow visualization).

$\mathrm{Su}-47$ was an inherently unstable aircraft that was kept in controlled flight using a fly-by-wire system The Su- 47 has exceptional maneuverability at subsonic speeds enabling the aircraft to alter its AoA and its flight path very quickly. The Su-47 has very high levels of agility with maintained stability and controllability at all angles of attack. The Su-47 has exceptionally high agility at subsonic speeds permitting the aircraft to alter its AoA and its flight track very fast, and it also retains maneuverability in high-speed flight. The Su-47 aircraft has great maneuverability with preserved stability and controllability at all AoA.

It is known that the nose is slightly flattened at the fore section and has a horizontal edge to optimize the aircraft's anti-spin characteristics. The wing boards of the Su- 47 are made of nearly $90 \%$ composites. The forward-swept mid wing has a high aspect ratio, which provides to long-distance performance. The leading-edge root extensions (LEX) blend smoothly to the wing panels, which are tailored with deflectable slats on the leading edge, that are the flaps and ailerons on the trailing edge.

According to several bulletins, the Eurofighter Typhoon aircraft has canards in front and delta wing. Its small size gives it high maneuverability that exceeds that of F-15's, F-16's \& Su-27's. The maximum speed of Mach 2. The technology is very advanced. It becomes one of the best engines currently in service, its small, agile, highly maneuverable, great acceleration and thrust/weight ratio. It is a medium range, twin-engine, multi-role, airsuperiority fighter. With its $3 \mathrm{D}$ thrust vectoring and canards and a sturdy airframe, it could be a deadly battle for the Typhoon.

The Eurofighter Typhoon has a double engine, canard-delta wing, multirole fighter. The Eurofighter Typhoon is an extremely agile aircraft, designed to be an enormously effective dogfighter in combat. The Typhoon had an intentionally relaxed stability design that made highly agile at both supersonic and low speeds. It has a four-layer digital fly-by-wire regulator system giving artificial stability, as manual operation only could not balance for the intrinsic instability. The fly-by-wire system is labeled as care-free and prevents the pilot from beyond the permitted maneuver envelope. The Typhoon, without after-burners, is capable of the supersonic cruise. A Typhoon, on a hot day, can supercruise at 1.5 Mach and manage to supercruise at 1.21 Mach with a combat load. Otherwise, the Eurofighter can launch weapons while under supercruise to extend their ranges via this running start.

Apart from the comments from the bulletins, the results of this experiment are the following. Figure 3 shows that greater vortex breakdowns are formed closer to the leading-edge main wing if the AoA value increases. At AoA= $20^{\circ}$, Figure $2 \mathrm{a}$ and $2 \mathrm{~b}$ showed that the vortex breakdown $(\mathrm{Vb})$ of the Su-47 model occurred on 13/15 part of the main wing and showed that the $\mathrm{Vb}$ of Typhoon aircraft models occurred on $22 / 25$ main wing. At $\mathrm{AoA}=50^{\circ}$, Figure $2 \mathrm{q}$ and $2 \mathrm{r}$ show that the $\mathrm{Vb}$ of Su-47 occurs in $1 / 5$ of the main wing. While Figure $2 \mathrm{~s}$ and $2 \mathrm{t}$ displayed that Typhoon has not formed vortex cores, surprisingly, $\mathrm{Su}-47$ has double vortex core due to its front swept wings

Figure 4 shows a comparison chart of $\mathrm{Cl}$ values against AoA on Sukhoi Su-47 and Eurofighter Typhoon aircraft models. Su-47 could perform lift change very abruptly. It could also perform angle of attack and flight path changes very quickly while still capable of maintaining its stability. Figure 4 shows that for the Typhoon aircraft model, there is no lift at $\mathrm{AoA} 45^{\circ}$, while for the Su-47 there is no lift at AoA 50 . It shows a comparison chart of Cd values against AoA on Sukhoi Su-47 and Eurofighter Typhoon aircraft models. It shows that Su-47 has very high drag compared against Eurofighter Typhoon. One can conclude that $\mathrm{Su}-47$ has dual vortex core on the FSW, that gives higher $\mathrm{Cl}$ and $\mathrm{Cd}$ than Eurofighter Typhoon.

\section{Conclusion}

The Su-47 which has front swept wings, therefore they have two vortex cores, a vortex core from the FSW end 
and a vortex core from the canard, each of which produces rolled-up vortices that induce lift coefficient or $\mathrm{Cl}$. While Typhoon only has one vortex core. Because $\mathrm{Su}-47$ has greater lift coefficient gives rise to the abrupt lift changes, during flight is capable of performing angle of attack and flight path changes very quickly and to maintain its stability fly-by-wire is needed in practice. Front swept wings mean improved stability at high angles of attack; it has a shorter take-off, a lower minimum flight speed, and landing distance. The Su-47 with no-deflection of the canard, the AoA $50^{\circ}$ there is no lift. Cd Su- 47 High Drag very high $\mathrm{Cl}$.

From the results of visualization, testing shows the stall event on the Sukhoi Su-47 Berkut plane model occurs at angles of attack $50^{\circ}$, while in the Eurofighter Typhoon plane model occurs at an AoA $45^{\circ}$. From the tests that have been carried out on the aircraft model similar to Sukhoi Su-47, the stall event begins to occur at an angle of attacks $50^{\circ}$ by showing the comparison data of the $\mathrm{Cl}$, max value with a $\mathrm{Cd}$ of $2.66: 2.40$. Whereas in the plane model similar to Eurofighter Typhoon the stall event began to occur at an angle of attack $45^{\circ}$ by showing the comparison data of $\mathrm{Cl}$ with a $\mathrm{Cd}$ of $1.48: 0.74$. In the future, the researches on the $\mathrm{Su}-47$ and Eurofighter Typhoon are needed with canard deflection at an angle of $-40^{\circ}$ up to $10^{\circ}$.

\section{Acknowledgment}

This research was funded by Universitas Gadjah Mada, Indonesia, under the contract 1859/UN1/DITLIT/DITLIT/LT/2018.

\section{References}

Boelens, O. J. (2012). CFD analysis of the flow around the X-31 aircraft at high angle of attack. Aerospace Science and Technology, 20(1), 38-51. https://doi.org/10.1016/j.ast.2012.03.003

Cezary Galinski, Lis, M., \& Hajduk, J. (2017). Electric Propulsion Concepts for an Inverted Joined. Energies, 10(762), 1-21. https://doi.org/10.3390/en10060762

Chen, M., Liu, P., Guo, H., \& Qu, Q. (2016). Effect of sideslip on high-angle-of-attack vortex flow over closecoupled canard configuration. Journal of Aircraft, 53(1), 217-230. https://doi.org/10.2514/1.C033305

Cotton, L. S. J., \& Bjarke, L. J. (1994). Flow-Visualization Study of the X-29A Aircraft at High Angles of Attack Using a 1 / 48-Scale Model Flow-Visualization Study of the X-29A Aircraft at High Angles of Attack Using a 1 / 48-Scale Model. Nasa Technical Memorandum. Edwards, California. Retrieved from https://www.nasa.gov/centers/dryden/pdf/88321main_H-1918.pdf

Dapper, T., Cabreira, V., \& Freitas, E. P. De. (2018). Development and Testing of a Low-Cost Instrumentation Platform for Fixed-Wing UAV Performance Analysis. Drones, 2, 19. https://doi.org/10.3390/drones2020019

Delfrate, J. H., Zuniga, F. A., \& Fisher, D. F. (1991). In-flight flow visualization with pressure measurements at low speeds on the NASA F-18 High Alpha Research Vehicle. In Vortex Flow Aerodynamics. NASA Dryden Flight Research Facility; Edwards, CA, United States. Retrieved from https://ntrs.nasa.gov/search.jsp?R=19920003791

Della Vecchia, P., \& Nicolosi, F. (2014). Aerodynamic guidelines in the design and optimization of new regional turboprop aircraft. Aerospace Science and Technology, 38, 88-104. https://doi.org/10.1016/j.ast.2014.07.018

Erickson, G. (1982). Water-Tunnel Studies of Leading-Edge Vortices. Journal of Aircraft, 19(6), 442-448. https://doi.org/10.2514/3.57414

Erm, L. P. (2003). Measurement of flow-induced pressures on the surface of a model in a flow visualization water tunnel. Experiments in Fluids, 35(6), 533-540. https://doi.org/10.1007/s00348-003-0667-0

Erm, L. P. (2007). Recent Aerodynamics Research in the DSTO Water Tunnel. In 16th Australasian Fluid Mechanics Conference (pp. 381-384). Crown Plaza, Gold Coast, Australia: School of Engineering, The University of Queensland.

Erm, L. P., \& Ol, M. V. (2012). An Assessment of the Usefulness of Water Tunnels for Aerodynamic Investigations (AR Number AR-015-530 No. DSTO-TR-2803, Air Vehicles Division DSTO Defence Science and Technology Organisation). Fishermans Bend Victoria. Retrieved from http://dspace.dsto.defence.gov.au/dspace/

Ghoreyshi, M., Cummings, R. M., Ronch, A. Da, \& Badcock, K. J. (2013). Transonic Aerodynamic Load Modeling of X-31 Aircraft Pitching Motions. AIAA Journal, 51(10), 2447-2464. https://doi.org/10.2514/1.J052309

Ghoreyshi, M., Korkis-Kanaan, R., Jirasek, A., Cummings, R. M., \& Lofthouse, A. J. (2016). Simulation validation of static and forced motion flow physics of a canard configured TransCruiser. Aerospace Science and Technology, 48, 158-177. https://doi.org/10.1016/j.ast.2015.11.008 
Id, B. Y., Förster, P., \& Id, S. H. (2018). A Generic Approach to Analyze the Impact of a Future Aircraft Design on the Boarding Process. Energies, 11(303), 1-12. https://doi.org/10.3390/en11020303

Jaroszewicz, A., Stachow, J., Sibilski, K., \& Zyluk, A. (2011). Water Tunnel Experimental Studies of Leading Edge Vortex Control on Delta Wing MAV. In 49th AIAA Aerospace Sciences Meeting including the New Horizons Forum and Aerospace Exposition (pp. 1-11). Aerospace Sciences Meetings. https://doi.org/10.2514/6.20111158

Jiao, B., Zafari, Z., Will, B., Ruggeri, K., \& Li, S. (2017). The Cost-Effectiveness of Lowering Permissible Noise Levels Around U. S . Airports. Int. J. Environ. Res. Public Health, 14, 1497. https://doi.org/10.3390/ijerph14121497

Lu, Z., \& Zhu, L. (2004). Study on Forms of Vortex Breakdown over Delta Wing. Chinese Journal of Aeronautics, 17(1), 13-16. https://doi.org/10.1016/S1000-9361(11)60196-9

Sandlin, D. R., \& Ramirez, E. J. (1991). Water Tunnel Flow Visualization Study of The Vortex Flow Structures on The F/A-18 Aircraft, (July).

Schütte, A., \& Rein, M. (2007). Experimental and numerical aspects of simulating unsteady flows around the X31 configuration. In 3rd International Symposium on Integrating CFD and Experiments in Aerodynamics (pp. 1-16). https://doi.org/10.1243/09544100JAERO387

Simpson, R. L. (2001). Junction Flows. Annual Review of Fluid Mechanics, 33(1), 415-443. https://doi.org/10.1146/annurev.fluid.33.1.415

Suarez, C. J., Malcolm, G. N., Kramer, B. R., Smith, B. C., \& Ayers, B. F. (1994). Development of a Multicomponent Force and Moment Balance for Water Tunnel Applications, Volume I.

Sutrisno, Rochmat, T. A., Wibowo, S. B., Iswahyudi, S., Wiratama, C., \& Kartika, W. (2018). The Flow Visualization CFD Studies of the Fuselage and Rolled-up Vortex Effects of the Chengdu J-10-like Fighter Canard. Modern Applied Science, 12(2), 148. https://doi.org/10.5539/mas.v12n2p148

Thompson, D. H. (1990). Water Tunnel Flow Visualisation of Vortex Breakdown Over The F/A-18 (AR-005-007 No. DST 88/034, Defence Science And Technology Organisation Aeronautical Research Laboratory). Melbourne Victoria.

Thompson, D. H. (1997). Effect of the Leading-Edge Extension ( LEX ) Fence on the Vortex Structure over the F / A-18.

Wibowo, S. B., Sutrisno, \& Rohmat, T. A. (2018). Water Tunnel Flow Visualization Due to Canard Deflection Effect on Aircraft to Improve Stall Delay Performance. In 4th International Conference on Science and Technology (ICST) (pp. 619-625). Yogyakarta, Indonesia: IEEE Xplore. https://doi.org/10.1109/ICSTC.2018.8528649

Wibowo, S. B., Sutrisno, Rohmat, T. A., Anwar, Z., Syadi, F. R., Mahardika, R., \& Naufal, W. F. (2018). An investigation into the use of GAMA water tunnel for visualization of vortex breakdown on the delta wing. In 9th International Conference on Thermofluids (p. 050007). Yogyakarta, Indonesia: AIP Conference Proceedings. https://doi.org/10.1063/1.5049998

Zafari, Z., Jiao, B., Will, B., Li, S., \& Muennig, P. A. (2018). The Trade-Off between Optimizing Flight Patterns and Human Health : A Case Study of Aircraft Noise in Queens, NY, USA. Int. J. Environ. Res. Public Health, 15, 1713. https://doi.org/10.3390/ijerph15081753

Zhang, T., Zhang, S., He, Y., Du, X., \& Ma, B. (2018). Research on Local Humidity Environment of Ground Parking Aircraft. Applied Sciences, 8, 1917. https://doi.org/10.3390/app8101917

\section{Copyrights}

Copyright for this article is retained by the author(s), with first publication rights granted to the journal.

This is an open-access article distributed under the terms and conditions of the Creative Commons Attribution license (http://creativecommons.org/licenses/by/4.0/). 